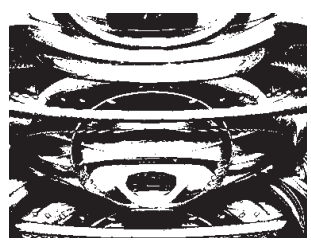

doi:10.5559/di.22.3.01

\title{
THE HEXACO \\ PERSONALITY DOMAINS IN THE CROATIAN SAMPLE
}

Toni BABAROVIĆ, Iva ŠVERKO

Institute of Social Sciences Ivo Pilar, Zagreb

UDK: 159.923.2.072.42

Izvorni znanstveni rad

Primlieno: 6. 6. 2013.

The paper examines Ashton and Lee's six-factor model of personality (2001; Lee \& Ashton, 2004). The Croatian version of HEXACO-PI-(R) has been applied on a sample of Croatian university students $(\mathrm{N}=1004)$. According to the data obtained, the designated six HEXACO factors were confirmed in the Croatian sample. Six HEXACO dimensions showed expected relations with Big Five personality traits. Gender differences in HEXACO personality domains are mainly in line with theoretical expectations. The results of our study confirm the validity of the HEXACO personality model in Croatia.

Keywords: HEXACO, personality, the Big Five, validity, Croatia

$\square$ Toni Babarović, Institute of Social Sciences Ivo Pilar, Marulićev trg 19/1, P. O. Box 277, 10001 Zagreb, Croatia. E-mail: Toni.Babarovic@pilar.hr

\section{INTRODUCTION}

In this article, we will present a study on the evaluation of the HEXACO personality model in Croatia. The model proposes the existence of six personality dimensions - Honesty-Humility $(\mathrm{H})$, Emotionality (E), eXtraversion (X), Agreeableness (A), Conscientiousness $(\mathrm{C})$, and Openness to Experience $(\mathrm{O})$. The new HEXACO model represents a reorganization of the Big Five/Five-Factor traits in which the additional dimension Honesty-Humility is included (Lee \& Ashton, 2004).

The HEXACO model of personality emerged from revisited analyses of lexical personality studies which revealed that personality space is better defined as six-dimensional, than five- 
DRUŠ. ISTRAŽ. ZAGREB GOD. 22 (2013), BR. 3, STR. $397-411$

BABAROVIĆ, T. ŠVERKO, I. THE HEXACO. -dimensional (Ashton \& Lee, 2007; Ashton et al., 2004; Ashton et al., 2006a). A common six-factor structure has emerged in personality lexicons of Dutch, French, German, Hungarian, Italian, Korean, and Polish languages (Ashton et al., 2004). Recent studies that have reanalysed the archival data recovered a similar six-dimensional structure in personality lexicons of English (Ashton, Lee, \& Goldberg, 2004), Greek (Ashton \& Lee, 2007), Croatian (Ashton, Lee, \& de Vries, 2005), Turkish (Wasti, Lee, Ashton, \& Somer, 2008), and Filipino (Ashton et al., 2006b). The positions of these six dimensions in the factor space were somewhat different from their traditional locations given by Big Five and Five-Factor models, which required a different theoretical interpretation of factors (Ashton \& Lee, 2001). Six personality dimensions were identified and named Honesty-Humility $(\mathrm{H})$, Emotionality $(\mathrm{E})$, eXtraversion $(\mathrm{X})$, Agreeableness (A), Conscientiousness (C), and Openness to Experience $(\mathrm{O})$, so their names suggest the acronym HEXACO. Dimensions Extraversion, Conscientiousness, and Openness to Experience were very similar to the same Big Five dimensions; dimensions Agreeableness and Emotionality resembled similar dimensions of the Big Five to a lesser degree; while Honesty-Humility turned out to be a new and original factor of the six-dimensional structure and therefore represented a major departure from the previous personality models.

The content of the HEXACO factors (Lee \& Ashton, 2004) will be briefly described here. Honesty-Humility is defined by honesty, fairness, sincerity, modesty, and lack of greed. This new personality dimension does not have its counterpart in the Big Five/Five-Factor models and represents new variance added to well-known personality models. Emotionality is defined by the following characteristics: anxiety, fearfulness, sentimentality, dependence, and emotional reactivity versus self-assurance, toughness, and bravery. This dimension is somewhat similar to the Big Five Emotional Stability factor. Extraversion is related to talkativeness, sociability, and cheerfulness versus shyness, passivity and quietness, and therefore it is very similar to Extraversion as defined in the Big Five. Agreeableness includes a nice and easy nature, tolerance, and kindness, versus being quick tempered, irritable, argumentative and critical. The content of this dimension is somewhat different from the Big Five Agreeableness, particularly because of its content of quick temper and irritability which in the Big Five resemble aspects of low Emotional Stability. Conscientiousness is defined by hard work, organization, carefulness, and thoroughness, and therefore it is almost identical to the Big Five Conscientiousness dimension. Openness to Experience is defined by imagination, including originality and creativity 
DRUŠ. ISTRAŽ. ZAGREB GOD. 22 (2013), BR. 3 STR. $397-411$

BABAROVIĆ, T. ŠVERKO, I.: THE HEXACO... traits, as well as intellectual curiosity or inquisitiveness. The intellect content, in the sense of general intelligence or mental ability, is not included. Thus, Openness to Experience just partly represents the Big Five Intellect/Imagination dimension.

Presented similarities and differences between the HEXACO and the Big Five/Five-Factor models provide opportunity to verify the convergent validity of HEXACO. The strongest correlations should be expected between the HEXACO factors of Extraversion and Conscientiousness and their Big Five counterparts. Further, relations between the HEXACO and Big Five dimensions Emotionality and Agreeableness should be somewhat weaker as these two HEXACO dimensions can be seen as 30 degrees re-rotation from the axis locations of the two corresponding factors in the Big Five model (Lee \& Ashton, 2004). A bit lower level of convergence between the HEXACO Openness to Experience and the Big Five Intellect/Imagination dimension is also expected. Finally, Honesty-Humility is supposed to be a unique and original personality dimension and therefore it is not expected to correlate highly with any personality dimensions in the Big Five.

The expected correlations were verified by Lee and Ashton (2004), who compared personality dimensions measured by the HEXACO-PI and IPIP. They found highest convergent validity for Extraversion $(r=0.86)$, followed by Conscientiousness $(r=0.83)$, Emotionality $(r=-0.74)$, and Agreeableness $(r=0.72)$. Somewhat lower correlation was found between IPIP Intellect/ Imagination and HEXACO Openness to Experience $(r=0.68)$. The relative independence and uniqueness of Honesty-Humility is empirically supported by low correlations with IPIP dimensions, where highest correlation of $r=0.31$ was found with dimension Pleasantness/Agreeableness (Lee \& Ashton, 2004). Also, similar results were obtained in another study (Ashton \& Lee, 2005). When using the Big Five Mini-Marker scales and IPIP measures, the strongest correlations between Honesty-Humility and the Big Five traits are found for the Big Five Agreeableness dimension: the correlations reached $r=0.26$ for the Big Five Mini-Marker, and $r=0.28$ for IPIP Big Five measure.

Similar results on relations among the HEXACO and Big Five personality dimensions were found in Korean and French speaking Canadian samples, particularly for Extraversion, Conscientiousness and Openness to Experience (Boies, Yoo, Ebacher, Lee, \& Ashton, 2004). In both samples very high correlations were found between the HEXACO and Big Five dimensions of Extraversion and Conscientiousness, and moderately high correlations between the HEXACO Openness to Experience and the Big Five Intellect/Imagination. However, in these samples, relations between the HEXACO dimensions of Emo- 
DRUŠ. ISTRAŽ. ZAGREB GOD. 22 (2013), BR. 3, STR. 397-411

BABAROVIĆ, T. ŠVERKO, I. THE HEXACO.

\section{METHOD}

\section{Respondents}

tionality and Agreeableness and their Big Five counterparts were not so clear. Both HEXACO Agreeableness and Emotionality moderately correlated with both the Big Five Agreeableness and Emotional Stability. The authors concluded that such ambiguous relations could be expected, as they are partly consistent with the proposed re-rotation of the Agreeableness and Emotional Stability factor axes. Also, a moderate correlation between Honesty-Humility and Big Five Agreeableness $(r=0.43)$ was also found in the French-speaking Canadian sample (Boies et al., 2004).

On the basis of theoretical interpretations suggested by Ashton and Lee (2001) and several empirical findings, substantial gender differences in the HEXACO personality dimensions can also be expected. A greater gender difference is expected in the Emotionality dimension, suggesting that women are more emotional than men (e.g. Lee \& Ashton, 2004; Lee, Ogunfowora, \& Ashton, 2005; Ashton \& Lee, 2009; de Vries, de Vries, de Hoogh, \& Feij, 2009). Also, significant differences are expected in the Honesty-Humility scale, where women should score higher (Lee \& Ashton, 2004; Ashton \& Lee, 2009; de Vries et al., 2009). Previous studies did not provide consistent findings for gender differences in Openness to Experience, Agreeableness and Conscientiousness.

Our intention was to examine the appropriateness of the HEXACO personality model in a Croatian sample. Therefore, we translated the HEXACO-PI-(R) into Croatian and assessed a large sample of Croatian university students. On the basis of the collected data, we examined the psychometric characteristics of the instrument: the internal reliability of HEXACO-PI-(R) scales, its factor structure, and interscale correlations. Then we examined the validity of the HEXACO model by relating its six personality dimensions to well established measures of the Big Five personality traits, and investigated the expected gender differences in the HEXACO personality domains.

The respondents were undergraduate and graduate students at the University of Zagreb (474 males and 529 females and one respondent who did not indicate his/her gender). They were mostly 19-26 years old $(\mathrm{Mdn}=22)$ and were majoring in different fields, such as psychology, computing and technology, law, economics. The total number of 1004 respondents was tested with the HEXACO-PI-(R), whereas on a smaller subsample 


\section{Instruments}

(1) TABLE 1

The list of

HEXACO-PI-R

dimensions and facets of 525 respondents an additional measure of the Big Factor domains was also applied.

\section{HEXACO-PI-(R) personality measure}

The HEXACO-PI-(R) is a measure of the six HEXACO personality traits (Ashton \& Lee, 2001, 2002; Ashton, Lee, \& Goldberg, 2004). It is the newer version of the previous HEXACO-PI instrument (Ashton \& Lee, 2008, 2009) and it comes in three forms: 200 -item, 100 -item and 60 -item, all available in a self-report and an observer report form. In the HEXACO-PI-(R), each personality dimension is represented with 4 personality facets (all represented in Table 1). In addition, the interstitial facet of Altruism is also included, but as it divides its loadings between Honesty-Humility, Emotionality, and Agreeableness, it is excluded when calculating six HEXACO scores. Therefore, the HEXACO-PI-(R) comprises a total of 25 personality facets.

In this study, the 100-item form was applied. In the 100-item form, each personality facet is measured with 4 personality items on a 5-point Likert scale. The total HEXACO scores are calculated as sums of ratings on associated items divided by number of items per scale. The Cronbach's alpha reliability estimates of the 100-item form of HEXACO-PI-(R) obtained in previous study were as follows: $\alpha_{H}=0.84 ; \alpha_{E}=0.83 ; \alpha_{X}=0.82$; $\alpha_{A}=0.82 ; \alpha_{C}=0.78 ; \alpha_{O}=0.84$ (Ashton \& Lee, 2008).

The HEXACO-PI-(R) was translated into Croatian by two translators. They translated all items separately and later discussed them to achieve a consensus on their precise meaning. After that, an independent experienced interpreter translated it back into English. The minor stylistic differences between the Croatian version and the original HEXACO-PI-(R) were discussed with authors Kibeom Lee and Michael Ashton, who approved the final back-translated Croatian version of the instrument.
Personality dimensions

$\mathrm{H}$ - Honesty-Humility

E - Emotionality

$X$ - Extraversion

A - Agreeableness

C - Conscientiousness

O - Openness to Experiences

\section{Facets}

Sincerity, Fairness, Greed Avoidance, Modesty Fearfulness, Anxiety, Dependence, Sentimentality Social Self-Esteem, Social Boldness, Sociability, Liveliness Forgiveness, Gentleness, Flexibility, Patience Organization, Diligence, Perfectionism, Prudence Aesthetic Appreciation, Inquisitiveness, Creativity, Unconventionality

Altruism 
DRUŠ. ISTRAŽ. ZAGREB GOD. 22 (2013), BR. 3, STR. 397-411

BABAROVIĆ, T. ŠVERKO, I. THE HEXACO..
International Personality Item Pool (IPIP)

The International Personality Item Pool is a measure of the Big Five domains - Extraversion, Agreeableness, Conscientiousness, Emotional Stability and Intellect. In this study, a short 50-item version with a 5-point Likert scale (Mlačić \& Goldberg, 2007) was applied. The previous studies confirmed a high reliability and validity of the Croatian version of the IPIP-50 (Mlačić, Milas, \& Kratohvil, 2007). In this sample, the Cronbach's alpha reliability estimates were high $(\alpha$ extr $=0.89 ; \alpha$ agree $=0.86$; $\left.\alpha \operatorname{cosc}=0.82 ; \alpha_{e m o t}=0.89 ; \alpha_{\text {intel }}=0.83\right)$ and the factor structure closely resembled the original five-dimensional model.

\section{Administration procedure}

The data was collected on-line, and participants were recruited through e-mail and facebook invitations. The response was voluntary and no feedback or incentives were given to respondents.

\section{RESULTS}

\section{Scale descriptives, reliability and intercorrelations}

The correlations among raw scale scores of the HEXACO-PI(R) personality dimensions are presented in Table 1, together with Mean, Standard deviation and Cronbach's alpha reliability coefficient obtained for each scale. The reliability of the six personality dimensions was very good, as Cronbach alpha coefficients varied from 0.78 to 0.85 (Table 2). The six personality scales were mainly unrelated, with the highest correlations found among Agreeableness and Honesty-Humility, Agreeableness and Emotionality, and Openness to Experience and Honesty-Humility of $0.24,-0.23$, and 0.21 , respectively.

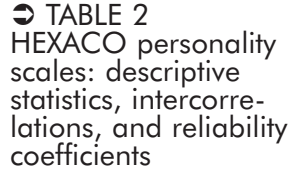

\begin{tabular}{lcccccc}
\hline & $\mathrm{H}$ & $\mathrm{E}$ & $\mathrm{X}$ & $\mathrm{A}$ & $\mathrm{C}$ & $\mathrm{O}$ \\
\hline $\mathrm{H}$ & $(0.83)$ & $0.16^{* *}$ & -0.01 & $0.24^{* *}$ & $0.08^{*}$ & $0.22^{* *}$ \\
$\mathrm{E}$ & & $(0.78)$ & $-0.06^{*}$ & $-0.23^{* *}$ & $0.07^{*}$ & $0.13^{* *}$ \\
$\mathrm{X}$ & & & $(0.82)$ & 0.05 & $0.16^{* *}$ & $0.17^{* *}$ \\
$\mathrm{~A}$ & & & & $(0.85)$ & -0.01 & -0.05 \\
$\mathrm{C}$ & & & & & $(0.83)$ & $0.13^{* *}$ \\
$\mathrm{O}$ & & & & & & $(0.83)$ \\
$\mathrm{M}$ & 3.34 & 3.16 & 3.53 & 2.81 & 3.50 & 3.50 \\
$\mathrm{Sd}$ & 0.61 & 0.59 & 0.55 & 0.55 & 0.50 & 0.62 \\
\hline
\end{tabular}

Note. Listwise $\mathrm{N}=970,{ }^{*} \mathrm{p}<0.05,{ }^{* *} \mathrm{p}<0.0$. Alpha coefficients are presented in brackets in diagonal. The raw scale scores are calculated as sum of ratings on associated items divided by number of items per scale. 


\section{The HEXACO structure}

The 25 personality facets were submitted to principal component analysis. The first eight eigenvalues were as follows: 3.69 , $2.97,2.64,2.09,1.94,1.28,0.95,0.92$. The obvious decrease in eigenvalues occurred between the sixth and the seventh component. Both Kaiser-Guttman criterion and Scree-test clearly yielded the six-factor solution, which accounted for $58.4 \%$ of the variance of personality facets. The six factor solution was also confirmed by parallel analysis. According to parallel analysis, six components should be retained as their eigenvalues exceeded the upper bound of mean random data eigenvalues. The sixth observed eigenvalue of 1.28 still exceeds the

(1) TABLE 3

The six factor structure of 25 personality facets: rotated solution 95th percentile random data eigenvalue of 1.17 , whereas the seventh observed eigenvalue of 0.95 is within the confidence interval (95th percentile 1.14).

\begin{tabular}{|c|c|c|c|c|c|c|}
\hline & $\mathrm{H}$ & $\mathrm{E}$ & $X$ & A & $\mathrm{C}$ & $\mathrm{O}$ \\
\hline Sincerity & $\underline{0.73}$ & -0.13 & 0.04 & -0.08 & 0.00 & 0.10 \\
\hline Fairness & $\overline{0.64}$ & 0.17 & 0.01 & 0.07 & 0.33 & 0.11 \\
\hline Greed Avoidance & $\underline{0.77}$ & 0.08 & -0.06 & 0.13 & -0.05 & 0.18 \\
\hline Modesty & $\underline{0.66}$ & 0.14 & -0.09 & 0.24 & -0.17 & -0.12 \\
\hline Fearfulness & 0.03 & $\underline{0.60}$ & -0.22 & -0.15 & 0.02 & -0.10 \\
\hline Anxiety & -0.03 & $\underline{\underline{0.53}}$ & $-\underline{0.44}$ & -0.28 & 0.22 & 0.12 \\
\hline Dependence & -0.04 & $\overline{0.76}$ & $\overline{0.12}$ & -0.02 & -0.11 & -0.01 \\
\hline Sentimentality & 0.21 & $\underline{0.78}$ & 0.14 & 0.01 & 0.08 & 0.16 \\
\hline Social Self-Esteem & 0.00 & -0.19 & $\underline{0.75}$ & 0.04 & 0.16 & -0.03 \\
\hline Social Boldness & -0.05 & 0.00 & $\underline{0.66}$ & -0.21 & 0.06 & 0.23 \\
\hline Sociability & -0.04 & 0.30 & $\underline{0.73}$ & 0.03 & 0.00 & 0.00 \\
\hline Liveliness & 0.03 & 0.00 & $\overline{0.79}$ & 0.16 & 0.00 & 0.05 \\
\hline Forgivingness & 0.26 & -0.06 & $\overline{0.13}$ & $\underline{0.64}$ & -0.05 & 0.08 \\
\hline Gentleness & 0.14 & 0.08 & 0.06 & $\underline{0.70}$ & -0.10 & -0.15 \\
\hline Flexibility & -0.08 & 0.01 & -0.09 & $\underline{0.74}$ & 0.01 & -0.04 \\
\hline Patience & 0.06 & -0.36 & 0.04 & $\underline{0.70}$ & 0.14 & 0.06 \\
\hline Organization & -0.02 & 0.06 & 0.08 & $\overline{0.03}$ & $\underline{0.71}$ & -0.21 \\
\hline Diligence & 0.09 & 0.02 & 0.29 & -0.11 & $\overline{0.65}$ & 0.23 \\
\hline Perfectionism & -0.05 & 0.18 & -0.06 & -0.15 & $\underline{0.71}$ & 0.15 \\
\hline Prudence & 0.02 & -0.20 & -0.03 & 0.15 & $\underline{0.67}$ & 0.04 \\
\hline Aesthetic Appreciation & 0.19 & 0.28 & 0.02 & 0.02 & 0.06 & $\underline{0.79}$ \\
\hline Inquisitiveness & 0.03 & -0.18 & 0.01 & 0.00 & 0.17 & $\underline{0.54}$ \\
\hline Creativity & 0.04 & 0.09 & 0.20 & -0.03 & 0.03 & $\overline{0.76}$ \\
\hline Unconventionality & 0.07 & -0.01 & -0.02 & -0.05 & -0.09 & $\underline{0.80}$ \\
\hline Altruism & 0.40 & $\underline{0.48}$ & 0.29 & 0.28 & 0.12 & 0.13 \\
\hline VAF & 9.27 & 10.34 & 10.73 & 9.38 & 8.82 & 9.90 \\
\hline
\end{tabular}

Note. Saturations greater than 0.40 are underlined. The presented order of factors does not match the order of extraction. The variance accounted for (VAF) refers to rotated solution. 
DRUŠ. ISTRAŽ. ZAGREB GOD. 22 (2013), BR. 3, STR. $397-411$

BABAROVIĆ, T. ŠVERKO, I. THE HEXACO.
The extracted six components were rotated to both varimax and oblimin solutions. The varimax-rotated factors were almost identical to the oblimin-rotated factors (all the corresponding factor score correlations were above 0.988 ) which confirmed the orthogonality of the components. The clear and simple varimax-rotated factor structure is presented in Table 3 . According to the factor loadings, it can be seen that the extracted dimensions had a clear and expected underlying structure and that they strongly resembled the theoretical meaning of the six HEXACO dimensions.

All the personality facets had strong projections only on designated factors. The only exception is the Anxiety scale that had the strongest loading of 0.53 on Emotionality dimension as expected, but also a moderate loading of -0.44 on Extraversion. Moreover, the interstitial facet of Altruism had no clear orientation towards any personality dimension as expected, with maximal loadings of 0.48 on Emotionality and 0.40 on Honesty-Humility.

Moreover, the PCA yielded similar solutions in the female and male samples (results of these analyses can be sent on request). The similarity of factor solutions obtained in the gender samples is confirmed with Tucker's coefficients of congruence, which are almost of maximal value $(\mathrm{CCH}=0.93 ; \mathrm{CCE}=0.97$; $\left.C C x=0.97 ; C_{A}=0.97 ; C C C=0.96 ; C C o=0.93\right)$ and therefore indicate the identical structure of personality dimensions in both the male and female samples.

\section{Relation to the Big Five personality dimensions}

We further examined the correlations with the Big Five personality dimensions. The relations of the HEXACO personality domains and facets to the Big Five personality factors are presented in Table 4. It can be seen that the HEXACO personality dimensions Extraversion, Conscientiousness and Openness to Experience correlated with their Big Five counterparts $0.79,0.74$ and 0.70 , respectively, and that all their facets were related to the matching Big Five dimensions. The HEXACO Emotionality dimension correlated -0.51 with Emotional Stability of the Big Five model. Its facet of Anxiety was strongly related to Emotional Stability ( $r=-0.66)$, while other facets had moderate or just weak relations to the Big Five Emotional Stability. The HEXACO Agreeableness dimension was just weakly related to the matching Big Five Agreeableness dimension $(r=0.26)$, and it was even more strongly correlated to the Big Five Emotional Stability dimension $(r=0.42)$. The Honesty-Humility dimension was moderately related to the Big Five dimension of Agreeableness (0.38). 


\begin{tabular}{|c|c|c|c|c|c|}
\hline & $\mathrm{E}$ & A & $\mathrm{C}$ & ES & I \\
\hline Honesty-Humility & -0.14 & 0.38 & 0.03 & 0.05 & 0.01 \\
\hline Sincerity & -0.05 & 0.23 & 0.07 & 0.10 & 0.04 \\
\hline Fairness & -0.05 & 0.31 & 0.19 & 0.03 & 0.05 \\
\hline Greed Avoidance & -0.10 & 0.26 & -0.07 & 0.02 & 0.05 \\
\hline Modesty & -0.21 & 0.29 & -0.16 & -0.01 & -0.14 \\
\hline Emotionality & -0.04 & $\underline{0.44}$ & 0.09 & $-\underline{0.51}$ & -0.15 \\
\hline Fearfulness & -0.14 & $\overline{0.05}$ & 0.02 & $-\overline{0.38}$ & -0.30 \\
\hline Anxiety & -0.18 & 0.13 & 0.10 & $-\underline{0.66}$ & -0.04 \\
\hline Dependence & 0.11 & 0.38 & 0.00 & $-\overline{0.22}$ & -0.12 \\
\hline Sentimentality & 0.09 & $\underline{0.66}$ & 0.12 & -0.20 & 0.04 \\
\hline Extraversion & $\underline{0.79}$ & 0.32 & 0.11 & $\underline{0.56}$ & 0.33 \\
\hline Social Self-Esteem & $\underline{0.47}$ & 0.18 & 0.14 & $\underline{0.57}$ & 0.25 \\
\hline Social Boldness & $\overline{0.71}$ & 0.10 & 0.10 & $\overline{0.24}$ & 0.35 \\
\hline Sociability & $\overline{0.59}$ & $\underline{0.44}$ & 0.00 & 0.17 & 0.14 \\
\hline Liveliness & $\underline{0.52}$ & $\overline{0.26}$ & 0.03 & $\underline{0.61}$ & 0.20 \\
\hline Agreeableness & -0.06 & 0.26 & 0.02 & $\underline{0.42}$ & -0.01 \\
\hline Forgivingness & 0.06 & 0.25 & -0.01 & $\overline{0.30}$ & 0.01 \\
\hline Gentleness & -0.05 & 0.33 & -0.07 & 0.20 & -0.06 \\
\hline Flexibility & -0.11 & 0.09 & 0.04 & 0.20 & -0.13 \\
\hline Patience & -0.08 & 0.08 & 0.08 & $\underline{0.48}$ & 0.14 \\
\hline Conscientiousness & 0.07 & 0.18 & $\underline{0.74}$ & 0.05 & 0.19 \\
\hline Organization & -0.02 & 0.06 & $\overline{0.75}$ & -0.03 & -0.04 \\
\hline Diligence & 0.26 & 0.26 & $\overline{0.41}$ & 0.16 & 0.33 \\
\hline Perfectionism & 0.03 & 0.20 & $\underline{\overline{0.50}}$ & -0.18 & 0.21 \\
\hline Prudence & -0.08 & -0.01 & $\overline{0.38}$ & 0.18 & 0.08 \\
\hline Openness to Experience & 0.15 & 0.16 & -0.04 & 0.04 & $\underline{0.70}$ \\
\hline Aesthetic Appreciation & 0.06 & 0.20 & 0.07 & -0.04 & 0.47 \\
\hline Inquisitiveness & 0.01 & -0.02 & -0.02 & 0.11 & 0.33 \\
\hline Creativity & 0.27 & 0.16 & 0.02 & 0.07 & $\underline{0.66}$ \\
\hline Unconventionality & 0.09 & 0.14 & -0.20 & -0.03 & $\overline{0.59}$ \\
\hline Altruism & 0.16 & $\underline{0.71}$ & 0.14 & 0.12 & 0.14 \\
\hline
\end{tabular}

\section{(1) TABLE 4}

Correlations between HEXACO personality domains and facets and the Big Five personality factors
Note.

$\mathrm{N}=525$. E - Extraversion, A - Agreeableness, C - Conscientiousness, ES - Emotional Stability, I - Intellect. Correlations greater than 0.40 are underlined.

\section{Gender mean differences in personality}

Finally, gender mean differences in personality domains were analyzed as a final aspect of construct validity of the HEXACO instrument. As shown in Table 5, Cohen's d indicated a large difference in Emotionality in favor of women $(d=-1.14)$. Moderate differences in favor of women were also found in Openness to Experience $(d=-0.62)$ and Honesty-Humility $(d=-0.45)$. At last, a small, but substantial difference in Agreeableness was found in favor of men $(d=0.35)$. 


\begin{tabular}{|c|c|c|c|c|c|}
\hline & $\mathrm{M}_{\mathrm{M}}$ & $\mathrm{Sd}_{\mathrm{M}}$ & $\mathrm{M}_{\mathrm{F}}$ & $\mathrm{Sd}_{\mathrm{F}}$ & Cohen's $d$ \\
\hline Honesty-Humility & 3.20 & 0.63 & 3.46 & 0.56 & -0.45 \\
\hline Sincerity & 3.33 & 0.75 & 3.44 & 0.74 & -0.15 \\
\hline Fairness & 3.11 & 1.00 & 3.64 & 0.90 & -0.56 \\
\hline Greed Avoidance & 2.99 & 0.95 & 3.33 & 0.82 & -0.38 \\
\hline Modesty & 3.35 & 0.81 & 3.44 & 0.65 & -0.12 \\
\hline Emotionality & 2.86 & 0.49 & 3.44 & 0.53 & -1.14 \\
\hline Fearfulness & 2.54 & 0.68 & 3.11 & 0.74 & -0.81 \\
\hline Anxiety & 3.10 & 0.73 & 3.51 & 0.77 & -0.55 \\
\hline Dependence & 2.84 & 0.82 & 3.41 & 0.88 & -0.66 \\
\hline Sentimentality & 2.98 & 0.75 & 3.72 & 0.75 & -0.99 \\
\hline Extraversion & 3.48 & 0.55 & 3.58 & 0.54 & -0.18 \\
\hline Social Self-Esteem & 3.73 & 0.68 & 3.70 & 0.66 & 0.05 \\
\hline Social Boldness & 2.89 & 0.80 & 3.00 & 0.82 & -0.14 \\
\hline Sociability & 3.78 & 0.67 & 3.96 & 0.63 & -0.27 \\
\hline Liveliness & 3.50 & 0.74 & 3.66 & 0.77 & -0.21 \\
\hline Agreeableness & 2.91 & 0.53 & 2.72 & 0.55 & 0.35 \\
\hline Forgivingness & 2.60 & 0.75 & 2.57 & 0.73 & 0.05 \\
\hline Gentleness & 3.22 & 0.67 & 3.05 & 0.69 & 0.24 \\
\hline Flexibility & 2.65 & 0.69 & 2.48 & 0.67 & 0.25 \\
\hline Patience & 3.19 & 0.89 & 2.79 & 0.84 & 0.46 \\
\hline Conscientiousness & 3.42 & 0.51 & 3.49 & 0.49 & -0.14 \\
\hline Organization & 3.33 & 0.76 & 3.45 & 0.78 & -0.16 \\
\hline Diligence & 3.68 & 0.68 & 3.82 & 0.64 & -0.22 \\
\hline Perfectionism & 3.53 & 0.66 & 3.65 & 0.68 & -0.17 \\
\hline Prudence & 3.14 & 0.72 & 3.05 & 0.70 & 0.11 \\
\hline Openness to Experience & 3.30 & 0.62 & 3.67 & 0.57 & -0.62 \\
\hline Aesthetic Appreciation & 2.88 & 0.94 & 3.74 & 0.79 & -0.99 \\
\hline Inquisitiveness & 3.44 & 0.80 & 3.38 & 0.74 & 0.08 \\
\hline Creativity & 3.38 & 0.86 & 3.82 & 0.83 & -0.53 \\
\hline Unconventionality & 3.53 & 0.74 & 3.75 & 0.69 & -0.30 \\
\hline Altruism & 3.58 & 0.64 & 3.86 & 0.62 & -0.44 \\
\hline
\end{tabular}

i TABLE 5

Gender differences in HEXACO personality domains and facets
Note. According to Cohen's (1988) interpretation of effect size, effect sizes around 0.2 are considered small, 0.5 medium, and 0.8 large. In our data negative values indicate differences in favor of women, while positive values indicate differences in favor of men.

\section{DISCUSSION}

Our results show that the Croatian version of the HEXACO-PI-(R) is a reliable measure of the six personality dimensions. The Cronbach's alpha internal reliability coefficients obtained in our sample ranged from 0.78 to 0.85 . The observed coefficients are in line with reliability coefficients of longer and shorter versions of the HEXACO instrument, which vary from 0.89 to 0.92 for HEXACO-PI 192-item form (Lee \& Ashton, 2004) and from 0.77 to 0.80 for HEXACO-60 (Ashton \& Lee, 2009). 
DRUŠ. ISTRAŽ. ZAGREB GOD. 22 (2013), BR. 3 STR. $397-411$

BABAROVIĆ, T. ŠVERKO, I.: THE HEXACO...
The HEXACO personality domains, expressed as raw scale scores, are weakly correlated and represent distinct constructs, as expected. The highest correlation among the six personality scales was found among Agreeableness and Honesty-Humility, Agreeableness and Emotionality, and Openness to Experience and Honesty-Humility, with each pair sharing just up to $5 \%$ of common variance. Similar weak relations among the HEXACO types were also observed in previous studies on Canadian samples (Ashton \& Lee, 2009; Lee \& Ashton, 2004), and Canadian francophone and Korean samples (Boies et al., 2004).

The factor structure of the Croatian HEXACO-PI-(R) was close to expectations and similar to earlier findings. The principal component analysis with Varimax rotation clearly yielded the expected six-factor solution which accounted for $58.4 \%$ of variance of 25 personality facets. However, in the original HEXACO-PI, six factors extracted by principal axis factoring explained a greater percentage of variance of personality facets $(63.2 \%$, Lee \& Ashton, 2004), which is likely to be a result of two-times longer and therefore more reliable HEXACO-PI scales.

In our data, all personality facets had loadings on expected personality dimensions (Table 3), as in the original HEXACO-PI (Lee \& Ashton, 2004). Also, our findings confirmed that Altruism is the interstitial facet, as it showed weak to moderate loadings on all personality dimensions, as expected. The only small departure from the original model can be seen in the position of the Anxiety facet, which had the strongest loading of 0.53 on the designated Emotionality dimension, but also a moderate negative loading of -0.44 on the Extraversion dimension. The reason for this unexpected loading of Anxiety facet on Extraversion is the newly-introduced Social Self-Esteem facet of Extraversion dimension which replaced former Expressiveness facet from HEXACO-PI. Social Self-Esteem facet turned out to be moderately related to Anxiety facet ( $r=-0.37$; facet intercorrelations can be sent on request) and therefore was responsible for the common variance of Anxiety facet and Extraversion scale. According to the apparent six-factor solution, the personality dimensions of Honesty-Humility, Emotionality, Extraversion, Agreeableness, Conscientiousness and Openness to Experience have been firmly confirmed in the Croatian sample. Moreover, they are also invariant across gender, as confirmed by Tucker's coefficients of congruence.

The relations among the HEXACO personality domains and the Big Five personality factors indicate expected relations (Table 4). As expected, the HEXACO-PI-(R) dimensions of Extraversion, Conscientiousness and Openness to Experience are strongly related to their Big Five counterparts $(0.79,0.74$ 
DRUŠ. ISTRAŽ. ZAGREB GOD. 22 (2013), BR. 3, STR. $397-411$

BABAROVIĆ, T. ŠVERKO, I. THE HEXACO.. and 0.70 , respectively), which corresponds to theoretical expectations and empirical findings (Lee \& Ashton, 2004; Boies et al., 2004). Also, moderate correlations of the HEXACO Emotionality dimension to the Big Five Emotional Stability $(-0.51)$ and Agreeableness (0.44) were observed, which highly correspond to theoretical expectations (Lee \& Ashton, 2004) and findings of Boies et al. (2004). The HEXACO Agreeableness has a bit weaker relation to the Big Five Agreeableness (0.26) and moderate relation to Emotional Stability (0.42), and therefore just partly matches previous expectations (Lee \& Ashton, 2004; Boies et al., 2004). This low correlation between Agreeableness in the two personality models is a result of different content of two Agreeableness scales. Agreeableness dimension in the Big Five model is defined by willingness to help people, generousness and helpfulness, which are closely related to Altruism. In the HEXACO-PI-(R), Agreeableness is defined by facets of Forgiveness, Gentleness, Flexibility, and Patience, which are a bit different from the concept of Altruism. This content mismatch is confirmed by our results. If we look at the correlation between the Altruism HEXACO interstitial scale and the IPIP scale of Agreeableness, the relation is noticeable (0.71). Then again, the factor structure of HEXACO-PI-(R) facets shows that Altruism is mostly unrelated to Agreeableness scale and its facets (Table 3). Thus, it is obvious that the Big Five Agreeableness scale relates to the content of Altruism stronger than the HEXACO Agreeableness dimension.

The proposed novelty of the HEXACO model, the Honesty-Humility dimension, turned to be mainly unrelated to all Big Five factors, except for the moderate relation to the Big Five Agreeableness dimension $(r=0.38)$. Similar relations among the HEXACO Honesty-Humility dimension and different Big-Five personality markers or factors are found in other studies which also stress the uniqueness of the Honesty-Humility dimension (Ashton \& Lee, 2009; Boies et al., 2004; Lee \& Ashton, 2004; Ashton \& Lee, 2005). However, the conclusion on relative originality and uniqueness of Honesty-Humility as personality dimension can be generalized only to the IPIP measure of the Big Five personality traits. For example, the NEO-PI-R measure of the Five Factor personality model contains facets of Agreeableness which correspond very closely to Honesty-Humility (particularly NEO facets Straightforwardness and Modesty). Therefore the usage of the NEO-PI-R instead of the IPIP could possibly lead to different conclusions on independence and originality of the HEXACO Honesty-Humility dimension in personality space.

Finally, we analyzed gender differences in personality domains. Females obtained higher scores than males on Emo- 
DRUŠ. ISTRAŽ. ZAGREB GOD. 22 (2013), BR. 3 STR. $397-411$

BABAROVIĆ, T. ŠVERKO, I.: THE HEXACO.. tionality $(d=-1.14)$, Openness to Experience $(d=-0.62)$ and Honesty-Humility $(d=-0.45)$, while males scored higher on Agreeableness dimension $(d=0.35)$. In previous studies, it was systematically observed that females scored higher than males on Emotionality and Honesty-Humility for approximately 1 $S d$ and 0.50 Sd, respectively (Lee \& Ashton, 2004; Ashton \& Lee, 2009), which was also the case in our data. Also, in previous studies no gender differences were observed in Extraversion (Lee \& Ashton, 2004; Ashton \& Lee, 2009), which was also confirmed by our data. Previous studies did not provide consistent findings for gender differences in Openness to Experience, Agreeableness and Conscientiousness, and therefore no systematic expectations could be derived. Our results are in line with the most prominent findings on gender differences in the HEXACO personality dimensions, and therefore they can serve as a support of the construct validity of the HEXACO-PI-(R) in the Croatian sample.

In sum, our findings firmly suggest that the HEXACO-PI-(R) is an adequate framework for explaining the personality of Croatian students and a valid measure of six broad personality dimensions. In addition to the well-known personality inventories, the HEXACO-PI-(R) provides new information by introducing the Honesty-Humility dimension to the common five-factor personality space.

\section{REFERENCES}

Ashton, M. C., \& Lee, K. (2001). A theoretical basis for the major dimensions of personality. European Journal of Personality, 15(5), 327-353. doi:10.1002/per.417

Ashton, M. C., \& Lee, K. (2002). Six independent factors of personality variation: A response to Saucier. European Journal of Personality, 16(1), 63-75. doi:10.1002/per.433

Ashton, M. C., \& Lee, K. (2005). Honesty-Humility, the Big Five, and the Five-Factor Model. Journal of Personality, 73(5), 1321-1353. doi:10. 1111/j.1467-6494.2005.00351.x

Ashton, M. C., \& Lee, K. (2007). Empirical, theoretical, and practical advantages of the HEXACO model of personality structure. Personality and Social Psychology Review, 11(2), 150-166. doi:10.1177/ 1088868306294907

Ashton, M. C., \& Lee, K. (2008). The prediction of Honesty-Humilityrelated criteria by the HEXACO and Five-Factor Models of personality. Journal of Research in Personality, 42(5), 1216-1228. doi:10. 1016/j.jrp.2008.03.006

Ashton, M. C., \& Lee, K. (2009). The HEXACO-60: A short measure of the major dimensions of personality. Journal of Personality Assessment, 91(4), 340-345. doi:10.1080/00223890902935878

Ashton, M. C., Lee, K., \& de Vries, R. E. (2005). Six factors in the Croatian personality lexicon. Unpublished manuscript. 
DRUŠ. ISTRAŽ. ZAGREB GOD. 22 (2013), BR. 3, STR. $397-411$

BABAROVIĆ, T. ŠVERKO, I. THE HEXACO..
Ashton, M. C., Lee, K., \& Goldberg, L. R. (2004). A hierarchical analysis of 1,710 English personality-descriptive adjectives. Journal of Personality and Social Psychology, 87(5), 707-721. doi:10.1037/0022-3514. 87.5.707

Ashton, M. C., Lee, K., de Vries, R. E., Perugini, M., Gnisci, A., \& Sergi, I. (2006a). The HEXACO model of personality structure and indigenous lexical personality dimensions in Italian, Dutch, and English. Journal of Research in Personality, 40(6), 851-875. doi:10.1016/j.jrp. 2005.06.003

Ashton, M. C., Lee, K., de Vries, R. E., Szarota, P., Marcus, B., Wasti, S. A., et al. (2006b). Lexical studies of personality structure: An examination of six-factor solutions. Paper presented at the 13th European Conference on Personality, Athens, Greece.

Ashton, M. C., Lee, K., Perugini, M., Szarota, P., De Vries, R. E., Di Blas, L., Boies, K., \& De Raad, B. (2004). A six-factor structure of personality-descriptive adjectives: Solutions from psycholexical studies in seven languages. Journal of Personality and Social Psychology, 86(2), 356-366. doi:10.1037/0022-3514.86.2.356

Boies, K., Yoo, T. Y., Ebacher, A., Lee, K., \& Ashton, M. C. (2004). Psychometric properties of the French and Korean versions of the HEXACO Personality Inventory. Educational and Psychological Measurement, 64 (6), 992-1006. doi:10.1177/0013164404267277

Cohen, J. (1988). Statistical power analysis for the behavioral sciences (2nd ed.). Hillsdale, NJ: Lawrence Earlbaum Associates.

de Vries, R. E., de Vries, A., de Hoogh, A. H. B., \& Feij, J. A. (2009). More than the Big Five: Egoism and the HEXACO model of personality. European Journal of Personality, 23(8), 635-654. doi:10.1002/per.733

Lee, K., \& Ashton, M. C. (2004). Psychometric properties of the HEXACO Personality Inventory. Multivariate Behavioral Research, 39 (2), 329-358. doi:10.1207/s15327906mbr3902_8

Lee, K., Ogunfowora, B., \& Ashton, M. C. (2005). Personality traits beyond the Big Five: Are they within the HEXACO space? Journal of Personality, 73(5), 1437-1463. doi:10.1111/j.1467-6494.2005.00354.x

Mlačić, B., \& Goldberg, L. R. (2007). An analysis of a cross-cultural personality inventory: The IPIP Big-Five factor markers in Croatia. Journal of Personality Assessment, 88(2), 168-177. doi:10.1080/002238 90701267993

Mlačić, B., Milas, G., \& Kratohvil, A. (2007). Adolescent personality and self-esteem: An analysis of self-reports and parental-ratings. Društvena istraživanja, 16(1-2), 213-236.

Wasti, S. A., Lee, K., Ashton, M. C., \& Somer, O. (2008). Six Turkish personality factors and the HEXACO model of personality structure. Journal of Cross-Cultural Psychology, 39(6), 665-684. doi:10.1177/0022022 108323783 
DRUŠ. ISTRAŽ. ZAGREB GOD. 22 (2013), BR. 3 STR. $397-411$

BABAROVIĆ, T. ŚVERKO, I.:

THE HEXACO...

\section{HEXACO dimenzije ličnosti u hrvatskom uzorku}

Toni BABAROVIĆ, Iva ŠVERKO

Institut društvenih znanosti Ivo Pilar, Zagreb

$\mathrm{U}$ ovom radu ispituje se prikladnost HEXACO modela ličnosti autora Ashtona i Leea (2001; Lee i Ashton, 2004). Hrvatska inačica instrumenta HEXACO-PI-(R) primijenjena je na uzorku studenata Zagrebačkoga sveučilišta $(N=1004)$. Na temelju provedenih analiza potvrđena je očekivana šesterofaktorska struktura te je šest ekstrahiranih HEXACO dimenzija pokazalo očekivanu povezanost s dimenzijama ličnosti modela Velikih pet. Utvrđene rodne razlike $u$ HEXACO dimenzijama ličnosti odgovarale su teorijskim očekivanjima i ranijim empirijskim nalazima. Na temelju svih rezultata zaključuje se kako je HEXACO model ličnosti, operacionaliziran instrumentom HEXACO-PI-(R), potvrđen $u$ hrvatskom uzorku.

Ključne riječi: HEXACO, ličnost, Velikih pet, valjanost, Hrvatska 